\title{
Simulate and Study the Effect of Compton Scattering Angle on the Radiography Inspection
}

\author{
Iman Tarik Al-Alawy ${ }^{a, *}$, Alaa B. Kadhim ${ }^{\mathrm{b}}$, Sura Salim Ahmed \\ ${ }^{a} A$ I-Mustansiriyah University, College of Science, Physics department, Baghdad - Iraq \\ bBaghdad University, College of Science, Physics department, Baghdad - Iraq \\ 'Technology University, Materials Engineering, Baghdad - Iraq \\ *Email: drimantarik@yahoo.com
}

\begin{abstract}
Keywords: Compton scattering, Radiography Inspection, Nondestructive test, Gamma ray inspection, Pipe detection.
\end{abstract}

\begin{abstract}
Radiography inspection have been used in this work to detects and image the corrosion in the outside surface of the pipe. Gamma ray with $0.662 \mathrm{MeV}$ from ${ }^{127} \mathrm{Cs}$ source have been chosen for this inspection while $\mathrm{NaI}(\mathrm{Tl})$ detector is use to detect and collect the scatter photons with radius $6 \mathrm{~cm}$. A simulation follow the history of photon by using Fortran Language and concerned on the effect of Compton scattering angle on the count rate of scatter photons and on the quality of the image. The Compton scattering angles that study are in the range from $\left(90^{\circ}-100^{\circ}\right)$ to $\left(170^{\circ}-180^{\circ}\right)$ with step $10^{\circ}$. The results show that the greater count rate of scattered photons is improved in the angle range $\left(90^{\circ}-100^{\circ}\right)$. Therefore, the count rate decreases with increasing the angle range especially within the range $\left(170^{\circ}-180^{\circ}\right)$ which has a minimum count rate and affect on the image resolution, then it could not distinguish between the corrosion and non-corrosion region.
\end{abstract}

\section{INTRODUCTION}

Radiography testing is used in a very wide range of applications including medicine, engineering, forensics, security, etc. [1, 2], and many researcher are used, worked, explored or simulated the principle of radiographic testing methods with different ways [3-10]. In Nondestructive Testing (NDT), radiography is one of the most important and widely used methods [1, 2, and 3]. Radiographic testing (RT) offers a number of advantages over other NDT methods, some as follows [1, 11, and 12]:

- $\quad$ Both surface and internal discontinuities can be detected and it is useful for thin sections.

- $\quad$ Significant variations in composition can be detected and it is suitable for any material.

- $\quad$ It has a very few material limitations.

- $\quad$ Can be used for inspecting hidden areas (direct access to surface is not required).

- $\quad$ Information is presented pictorially.

- A permanent record is provided which may be viewed at a time and place distant from the test.

- Very minimal or no part preparation is required.

- $\quad$ Good portability especially for gamma-ray sources.

While, the disadvantages of this method are [1, 11, and 12]:

- $\quad$ Generally an inability to inspect thick samples.

- $\quad$ Radiation sources can pose health and safety risks.

- $\quad$ The tedious film processing requirement of radiography and associated special facility requirements have traditionally been a distinct disadvantage; however, with the advent of digital imaging and computed radiography many of these limitations have been overcome.

Not suitable for automation, unless the system incorporates fluoroscopy with an image intensifier or other electronic aids.

In Radiographic Testing, the test-part is placed between the radiation source and film (or detector). The material density and thickness differences of the test-part will attenuate (i.e. reduce) the penetrating radiation through interaction processes involving scattering and/or absorption. The 
differences in absorption are then recorded on film(s) or through an electronic means $[13,14]$. This variation in the image darkness can be used to determine thickness or composition of material and would also reveal the presence of any flaws or discontinuities inside the material [1, 12]. In industrial radiography there are several imaging methods available, techniques to display the final image, i.e. Film Radiography, Real Time Radiography (RTR), Digital Radiography (DR) including Computed Radiography (CR), direct radiography, portable or stationary X-ray sources, 3D Computed Tomography (CT) and analytical X-ray [ 13, 15].

In general, RT is a method of inspecting materials for hidden flaws by using two different radioactive sources available for industrial; namely the X-ray generates from X-ray tube or machine and gamma rays are emitted by a radioactive isotope (Ir-192, Co-60, or Cs-137). These radiation sources use higher energy level, i.e. shorter wavelength, versions of the electromagnetic waves. Because of the radioactivity involved in radiography testing, it is of paramount importance to ensure that the Local Rules is strictly adhered during operation [1, 13, and 16].

When X-rays or gamma rays strike an absorber, some of the radiation is absorbed and another portion passes through un-deflected. It is the intensity variation of the un-deflected radiation from area to area in the specimen that forms the useful image in a radiograph. However, not all the radiation is either completely removed from the beam or transmitted. Some is deflected within the specimen from its original direction that is, it is scattered and is non-image-forming. This nonimage-forming scattered radiation, if not carefully controlled, will expose the film and thus tend to obscure the useful radiographic image. Another portion of the energy in the original beam is spent in liberating electrons from the absorber [2].

The aim of this work is to use the radiographic testing through simulation Compton scattering technique for detecting and imaging the corrosion in the outer surface of the pipe wall. The simulation is written by FORTRAN language to follow the photon path from ejection point (source), passing by interaction point with the pipe wall surface, until detected by the detector. Also the simulation focus on the effect of Compton scattering angles ranges on the quality and the resolution of the image. The results indicates that the smallest scattering range is an excellent angle range which can give the best quality imaging and resolution, so that the count rate of detected photons decrease with increasing the angle range.

\section{THE GEOMETRY AND SIMULATION PROGRAM}

\section{1. The Specimen Material and Dimension}

An iron pipe which used in this work with defect on its outside surface has a shape close to a circular with corrosion diameter (CD) of about $(8 \mathrm{~cm})$. The pipe has asbestos insulator, which is neglected in the calculation due to lower atomic number and density of its material. Moreover, the backscattered radiation from the insulator is almost constant along the pipe; corrosion takes place in the pipe wall. Hence, it will cause no significant interference. The geometry of (MCBS) technique that has been designed to be used in this work is illustrated in fig. 1. Where, a point source of gamma ray locates at different distances $\mathrm{SP}=4,6,8,10,12 \mathrm{~cm}$ from the pipe surface. The gamma photons which is incident vertically on the pipe surface, suffer scattering or multiple scattering after interaction with the tube material. The Compton scatter angle $\left(\Theta_{\text {Comp }}\right)$ is in the range $\left(130^{\circ}-140^{\circ}\right)$. Therefore, the scattered photons have been detected by the detector separated by $7 \mathrm{~cm}$ far from the source. The point source of $\gamma$-ray selected is ${ }^{137} \mathrm{Cs}$ with mono-energy $0.662 \mathrm{MeV}$. The NaI(Tl) scintillation gamma detector has been used with different radiuses $\mathrm{RD}=3,4,5,6,7,8,9,10,11$, $12.5 \mathrm{~cm}$. Both source and detector have been shielding by using lead $(\mathrm{Pb})$ to prevent registering the photons that come directly from the source without passing in the tube material, also both of them located at one side from the pipe surface. 


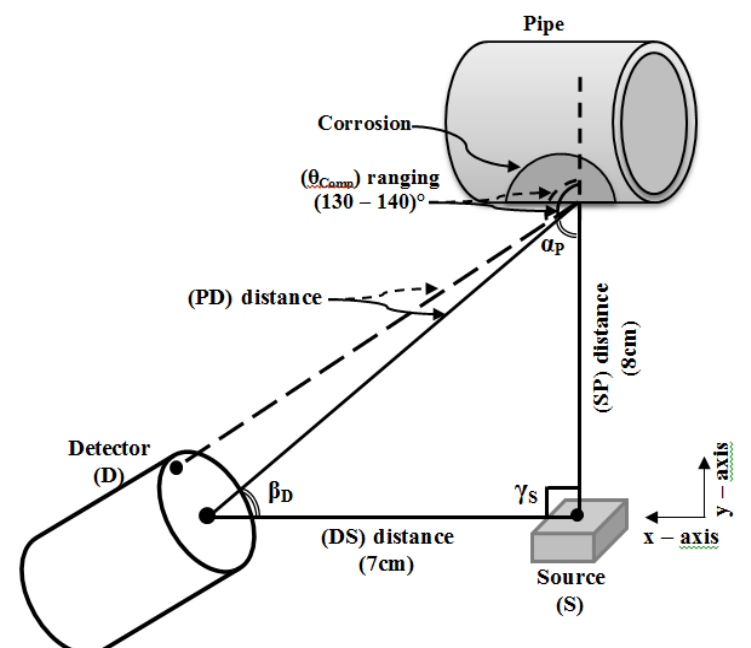

Fig. 1. The Geometry Technique.

\section{2. The Simulation Algorithm}

The algorithm of this work has a main program for the data preparation and interpolation, which has two main subroutines for non-corrosion (Fe region) and corrosion $\left(\mathrm{Fe}_{2} \mathrm{O}_{3}\right.$ region). The histories of (20000) photons emitted from the source are followed by using Monte Carlo simulation through FORTRAN90 using Compaq visual FORTRAN-CVF6.6 to determine the distribution of the backscatter radiation. A random number $(v)$ is used to obtain a uniform distribution within the range $0 \leq v \leq 1$. Simulation of photons history requires the following procedure:

(1) Supposing the pipe material consists of $\mathrm{Fe}$ and $\mathrm{Fe}_{2} \mathrm{O}_{3}$ to simplify the simulation required.

(2) Determine a region from the pipe surface with dimension $14 \mathrm{~cm} \times 5 \mathrm{~cm}$ and has corrosion with diameter $\mathrm{CD}=8 \mathrm{~cm}$ in the middle of this region. The Fe region divided into 70 sectors along the pipe with scanning increment $0.2 \mathrm{~cm}$. The corrosion area had been calculated implicit within sectors from 16 to 55 . Hence these data could be fed the program to detect the corrosion area.

(3) Assuming the total number of incident photons in each sector is 20000 photons, so the total incident photons for 70 sectors of Fe region are 1400000 photons and for 40 sectors of $\mathrm{Fe}_{2} \mathrm{O}_{3}$ region are 800000 photons.

(4) The mass attenuation coefficients $(\mu)$ values related to the energy range from $1 \mathrm{keV}$ to $1 \mathrm{MeV}$, have been taken for iron and iron oxide from XCOM database [17] respectively. The collected data have been used in the initiated to develop the interpolation function.

(5) In polar coordinate, a photon with incident gamma energy $\left(E_{0}\right)$ is emitted randomly as a function of polar angle $\left(\theta_{\mathrm{Ph}}\right)$ and azimuthal angle $\left(\varphi_{\mathrm{Ph}}\right)$. Cosine-sampling has been used for the polar angle $\left(\theta_{\mathrm{Ph}}\right.$ and uniform sampling for the azimuthal angle $\left(\varphi_{\mathrm{Ph}}\right)[18]$ :

$$
\begin{aligned}
& \theta_{\mathrm{Ph}}=\cos ^{-1}\left(2 v_{1}-1\right) \\
& \varphi_{\mathrm{Ph}}=\pi v_{2}
\end{aligned}
$$

(6) The energy of scattered photon is obtained by using Khan Method [19]. This method is used for random numbers sampling of the Klein-Nishina distribution. $\left(v_{\mathrm{i}}\right)$ are random numbers uniformly distributed in the range $0 \leq v_{i}<1$, (E) and (É) are the initial and final photon energies (in units of the electron rest mass energy), and (R) is the ratio (E/É) [18], as shown in fig. 2.

(7) Sampling for the actual path length (PL) of the photon in the material, is given by $[18,19]$ :

$$
\mathrm{PL}=-\frac{1}{\mu(\mathrm{E})} \ln \left(1-\mathrm{v}_{3}\right)
$$

(8) For multiple scattering of photons the program which has been installed in this work could be transform to different subroutines for determine the new scattering angles $(\alpha, \beta, \gamma)$ through the initial unit vector (n). 


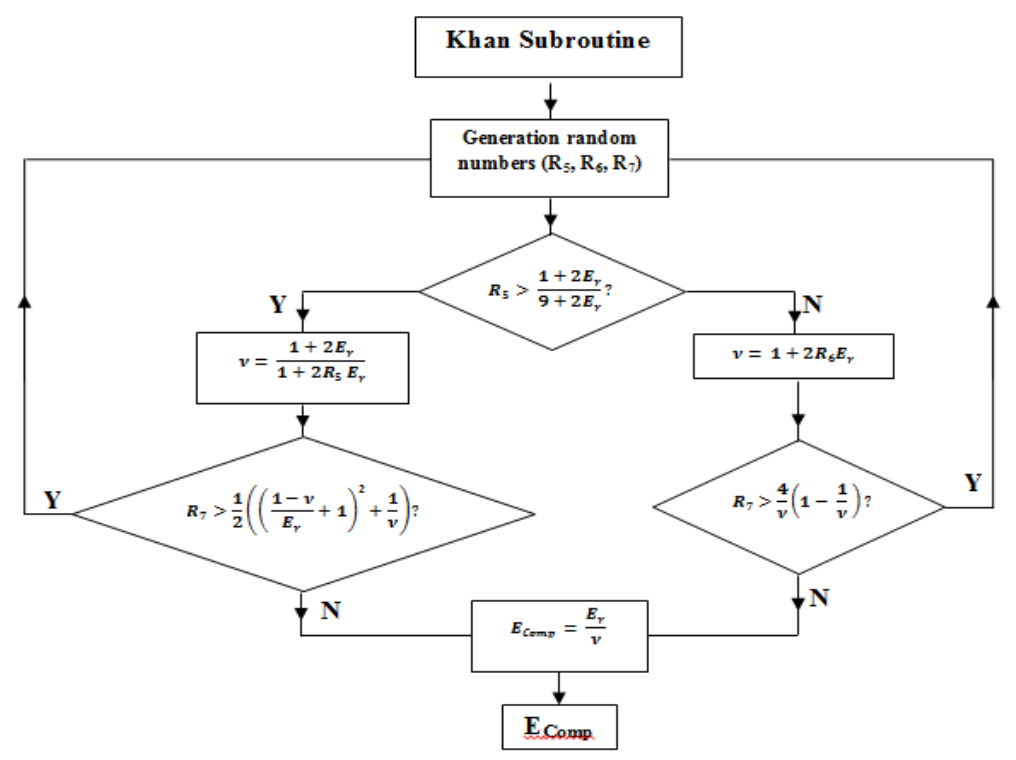

Fig. 2. Kahn method used for random sampling of the Klein-Nishina distribution. Ri are random numbers uniformly distributed in the range $0 \leq \mathrm{Ri}<1$, E $\gamma$ and EComp are the initial and final photon energies (in units of the electron rest mass energy), and $\mathrm{R}$ is the ratio of (E $\gamma / \mathrm{EComp})$ [18].

\section{RESULTS AND DISCUSSION}

The Compton scattering angle has great effect on the count rate of detected photons. Hence, the effected of variation of Compton scattering angle have been studied in this work by changing the angle in the simulation program starting from $\left(90^{\circ}-100^{\circ}\right)$ to $\left(170^{\circ}-180^{\circ}\right)$ step $\left(10^{\circ}\right)$.

The simulation images are shown in fig. 3 at detector radius $\mathrm{DR}=6 \mathrm{~cm}$. From these simulation images a fact has been arrived, that Compton angle is very important parameter affected on the count rate of detected/ registered scattered photons and on the resolution of the image. Where, at Compton angle range $\left(90^{\circ}-100^{\circ}\right)$ an excellent resolution simulation image with biggest count rate of detected scattered photons and can clearly distinguish between corrosion and noncorrosion region taking into consideration the limitation, shape and the area of corrosion region. This feature continuously occurred with the increasing in the Compton angle range, but the count rate will be decrease gradually with increasing the Compton angle up to the range $\left(170^{\circ}-180^{\circ}\right)$, where, the count rate of detected scattered photons slow down and the limits of corrosion region, its shape and area are very difficult to be determined as shown in fig. 3.

Table 1 summarize the relationship between the detected count rate with Compton angle at $\mathrm{DR}=6 \mathrm{~cm}$ for $\mathrm{Fe}$ and $\mathrm{Fe}_{2} \mathrm{O}_{3}$ regions. In table 1 there is a big difference between total number of scattered photons and the detected scattered photons, this is because the scattered photons represent the total number that happen inside the material and this is true when the condition of Compton angle is satisfied. Where, they represent the detected and undetected scattered photons, while the detected scattered photons represent the total number of scattered photons that satisfied all the conditions proposed in the simulation program. Also, table 1 shows that the total scattered photons increase gradually with increasing Compton angle range except at range $\left(170^{\circ}-180^{\circ}\right)$ because this range is approximately near to completely backscattering where most of scattered photons are escape. For more details fig. 4 illustrate the relationship between the count rate of detected scattered photons and the Compton angle ranges at detector radius DR $=6 \mathrm{~cm}$. Fig. 4 also shows that the count rate of detected scattered photons decrease when increasing Compton angle range which gives weak resolution for image. Hence, the Compton angle range $\left(90^{\circ}-100^{\circ}\right)$ is an excellent range because the detector can register maximum quantity of scattered photons. But in this work the ideal Compton angle is preferred to be in the range $\left(130^{\circ}-140^{\circ}\right)$ because the nondestructive testing (NDT) need a technique or a device that can be detect and monitor corrosion or any defect in objects which are under insulator or hidden, while other techniques cannot succeed because the detector position is almost nearby from the source. 


\section{CONCLUSIONS}

The radiography imaging technique using Compton backscattering provides a new method of (NDT), which is an excellent method for conserving the historical artifacts because of its ability to inspect pipes either with or without insulator and detect the corrosion product. The advantage of Compton backscattering imaging is to be found in its possibility to dell with the source and detector on one side of the object when access is limited, likes inspection of installed aircraft sections and inspection of large, filled storage tanks. Since the gamma ray backscattering is already used as an effective one-sided inspection tool for the detection of metal loss and the corrosion product in metals. Although at Compton backscattering angle $\left(\Theta_{\text {Comp }}=90^{\circ}-100^{\circ}\right)$ the count rate is maximum with high resolution but $\left(\Theta_{\mathrm{Comp}}=130^{\circ}-140^{\circ}\right)$ is identical and more sophisticated.
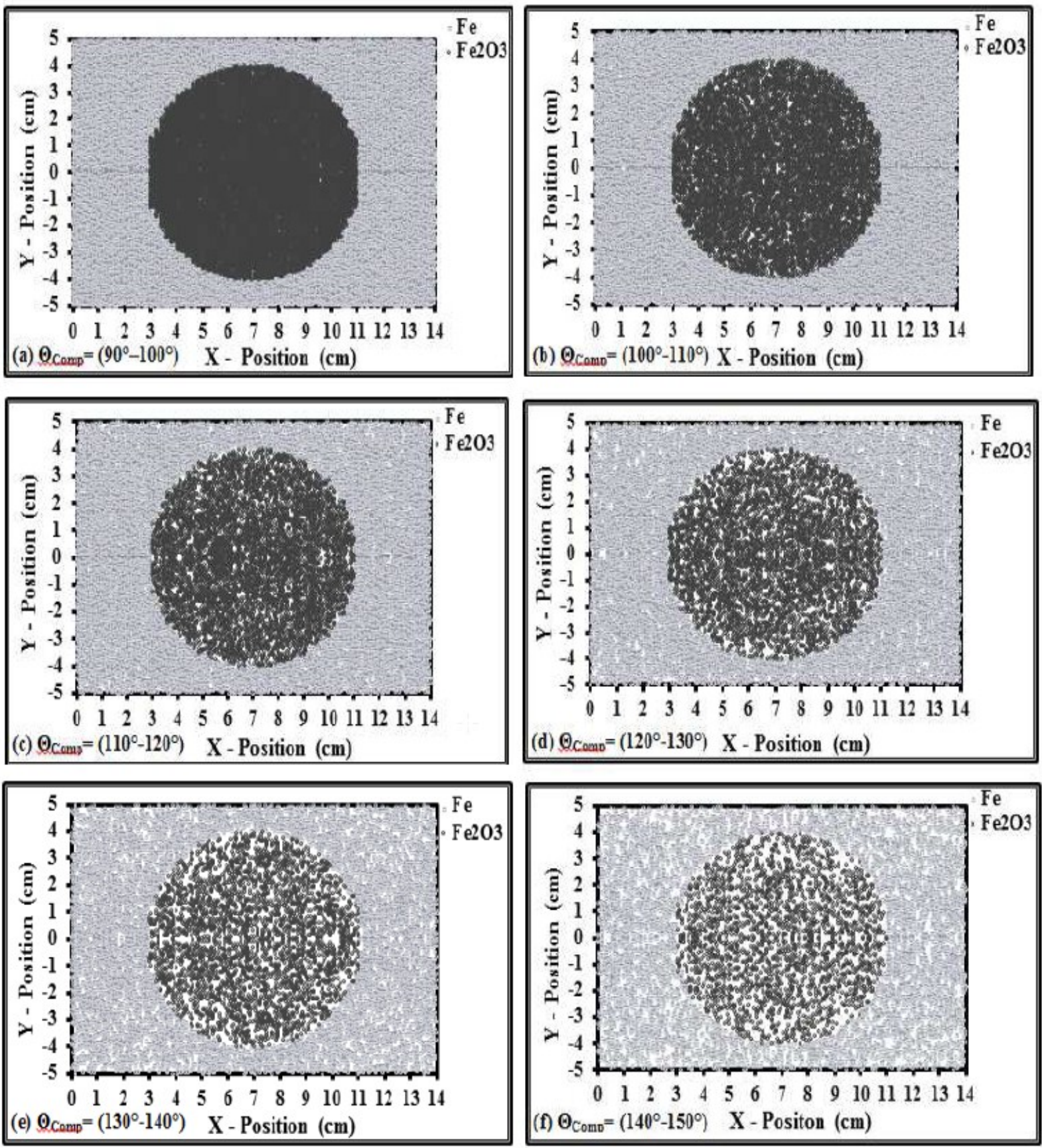

Fig. 3. The affected Compton angles variation on the simulation images results through increasing $\left(10^{\circ}\right)$ on the Compton range with detector radius $(6 \mathrm{~cm})$.
(a) $\Theta_{\text {Comp }}=\left(90^{\circ}-100^{\circ}\right)$.
(b) $\Theta_{\text {Comp }}=\left(100^{\circ}-110^{\circ}\right)$.
(c) $\Theta_{\mathrm{Comp}}=\left(100^{\circ}-120^{\circ}\right)$.
(d) $\Theta_{\text {Comp }}=\left(120^{\circ}-130^{\circ}\right)$.
(e) $\Theta_{\text {Comp }}=\left(130^{\circ}-140^{\circ}\right)$.
(f) $\Theta_{\mathrm{Comp}}=\left(140^{\circ}-150^{\circ}\right)$.
(g) $\Theta_{\mathrm{Comp}}=\left(150^{\circ}-160^{\circ}\right)$.
(h) $\Theta_{\mathrm{Comp}}=\left(160^{\circ}-170^{\circ}\right)$.
(i) $\Theta_{\mathrm{Comp}}=\left(170^{\circ}-180^{\circ}\right)$. 

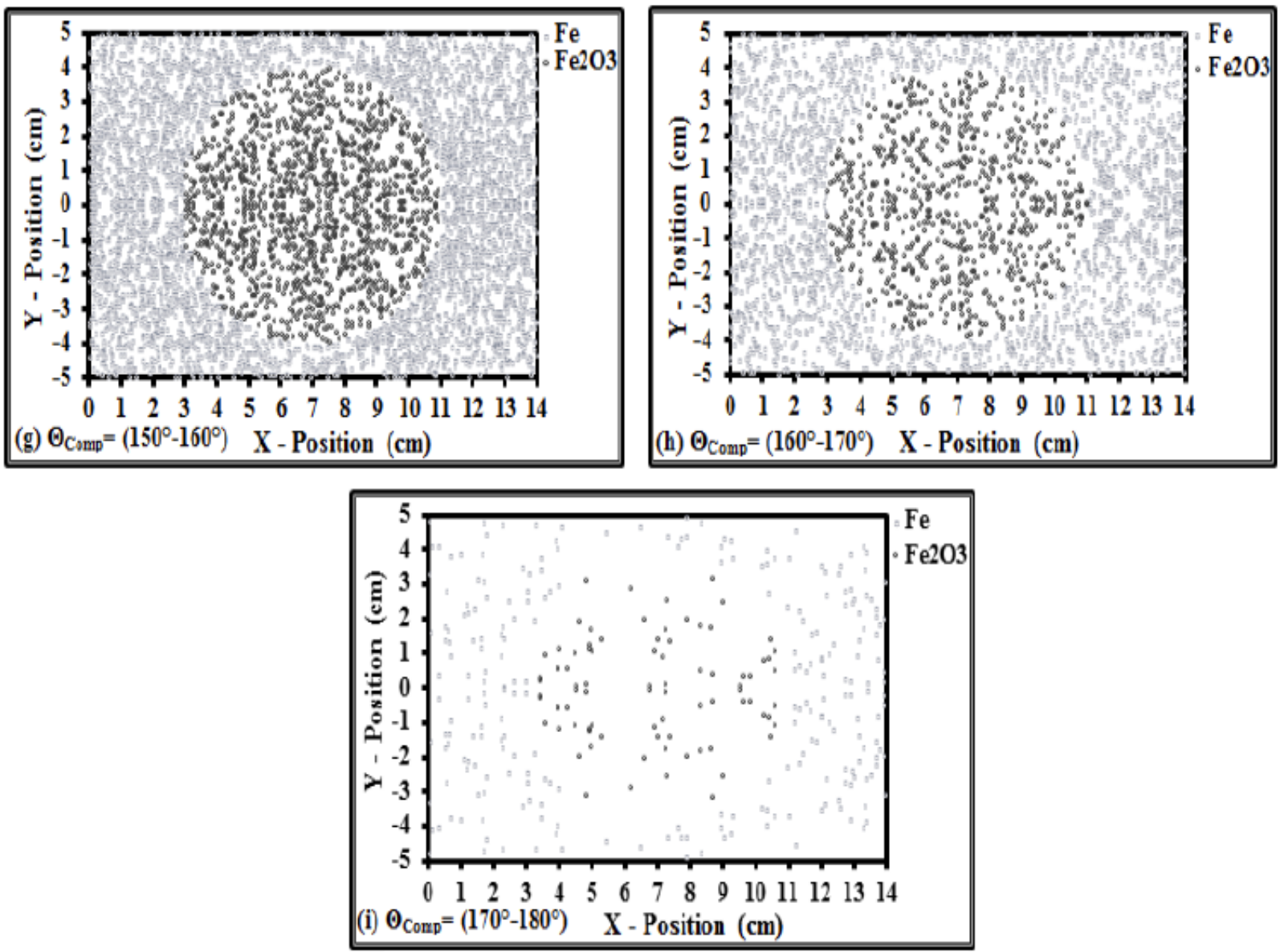

Fig. 3. To be continued (2/2).

Table 1 Total count rate of backscattering photons and registering backscattered photons at various Compton angles range with detector radius $6 \mathrm{~cm}$ for $\mathrm{Fe}$ and $\mathrm{Fe}_{2} \mathrm{O}_{3}$ region.

\begin{tabular}{|c|c|c|c|c|c|c|}
\hline \multirow{2}{*}{$\begin{array}{c}\Theta_{\text {Comp }} \text { (degree) } \\
\text { range }\end{array}$} & \multicolumn{2}{|c|}{$\begin{array}{c}\text { Total Scattered } \\
\text { photons }\end{array}$} & \multicolumn{2}{c|}{ MC Detected photons } & \multicolumn{2}{c|}{ PL Detected photons } \\
\cline { 2 - 7 } & $\mathrm{Fe}$ & $\mathrm{Fe}_{2} \mathrm{O}_{3}$ & $\mathrm{Fe}$ & $\mathrm{Fe}_{2} \mathrm{O}_{3}$ & $\mathrm{Fe}$ & $\mathrm{Fe}_{2} \mathrm{O}_{3}$ \\
\hline $90-100$ & 422204 & 236967 & 22825 & 10778 & 22664 & 10469 \\
\hline $100-110$ & 446608 & 248558 & 11511 & 4750 & 11507 & 4748 \\
\hline $110-120$ & 458917 & 253590 & 8192 & 3361 & 8190 & 3359 \\
\hline $120-130$ & 467486 & 257305 & 6233 & 2464 & 6233 & 2464 \\
\hline $130-140$ & 474547 & 259746 & 4567 & 1766 & 4567 & 1766 \\
\hline $140-150$ & 479140 & 261438 & 3102 & 1251 & 3101 & 1251 \\
\hline $150-160$ & 482315 & 262743 & 2012 & 745 & 2012 & 745 \\
\hline $160-170$ & 484425 & 263651 & 1112 & 387 & 111 & 387 \\
\hline $170-180$ & 392510 & 150764 & 121 & 42 & 121 & 42 \\
\hline
\end{tabular}

Note: Supposed the total number of incident photons in each sector is 20000 photons, so the total incident photons for 70 sectors of $\mathrm{Fe}$ region are 1400000 photons and for 40 sectors $\mathrm{Fe}_{2} \mathrm{O}_{3}$ region are 800000 photons. 


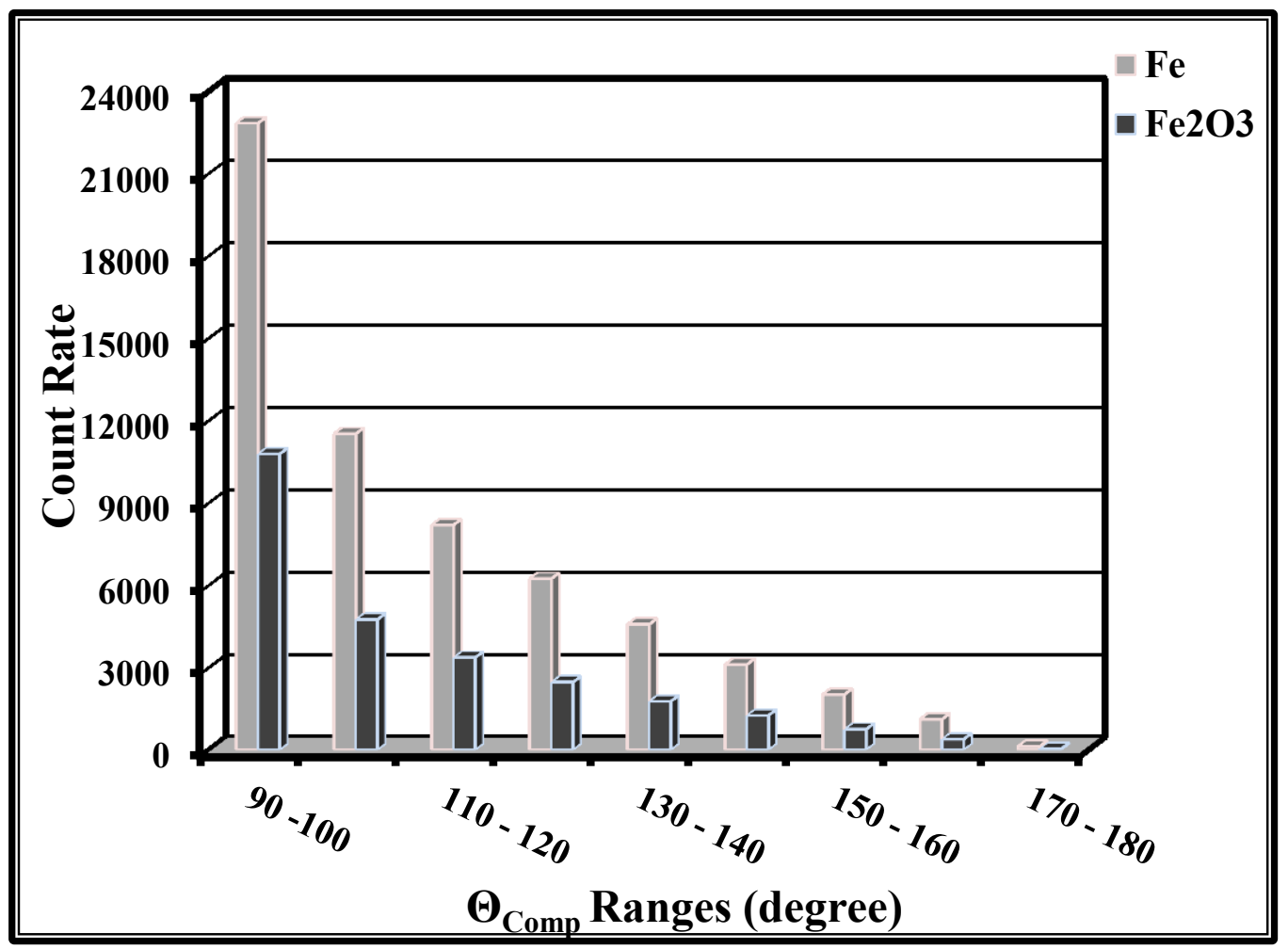

Fig. 4. The count rate of MC detected photons versus Compton angle ranges at detector radius $(6 \mathrm{~cm})$.

\section{Acknowledgments}

The authors thank the Dean of the College of Science and the Head of Department of Physics at Al-Mustansiriyah University for supporting this research.

\section{References}

[1] IAEA, "Guid Book for the Fabrication of Non-Destructive Testing (NDT) Test Specimens", published by International Atomic Energy Agency IAEA, Vienna, 2001.

[2] R. A. Quinn and C. C. Sigl, "Radiography in Modern Industry", $4^{\text {th }}$ edition, (C) Eastman Kodak Company, Rochester, New York, (1980).

http://www.kodak.com/eknec/documents/87/0900688a802b3c87/Radiography-in-ModernIndustry.pdf.

[3] G. Harding, "Inelastic Photon Scattering: Effects and Applications in Biomedical Science and Industry", Radiation Physics and Chemistry, 50 (1), (1997), 91-111.

[4] Kimiya Aoki and Yasuo Suga, "Application of Artificial Neural Network to Discrimination of Defect Type in Automatic Radiographic Testing of Welds", ISIJ International, 39(10), (1999), 1081-1087.

[5] N. Shengli, Z. Jun and H. Liuxing, "EGS4 Simulation of Compton Scattering for Nondestructive Testing", Proceedings of the Second International Workshop on EGS, 8.-12. August 2000, Tsukuba, Japan KEK Proceedings 200-20, (2000), 216-223.

[6] Uwe Zscherpel, Uwe Ewert, Bam, Silvia Infanzon, Aendur, Nasser Rastkhan, P. R. Vaidya, Isaac Einav and Sinasi Ekinci, "Radiographic Evaluation of Corrosion and Deposits in Pipelines: Results of an IAEA Co-ordinated Research Programme", ECNDT Mo.2.4.1, (2006), 1-14. 
[7] K. Banerjee and W.L. Dunn, "On X-ray Back-Scattering to Detect Hidden Cracks in MultiLayer Structures", Applied Radiation and Isotopes, 65(2), February (2007), 176-182.

[8] Edson Vasques Moreiraa, Heleno Ribeiro Simõesa, José Maurício Barbosa Rabellob, José Rubens de Camargob and Marcelo dos Santos Pereira, "Digital Radiography for the Inspection of Weld Seams of Pipelines - Better Sensitivity", Taylor and Francis Online, Welding International, 24(4), (2010), 249-257. http://www.tandfonline.com/doi/abs/10.1080/09507110902844022

[9] Alexander Boateng, K.A. Danso and C.P.K. Dagadu, "Non-Destructive Evaluation of Corrosion on Insulated Pipe Using Tangential Radiographic Technique", International Journal of Scientific and Technology Research, www.ijstr.org, 2(6), (2013), 7-13.

[10] S. Kolkoori, N. Wrobel, K. Osterloh, U. Zscherpel and U. Ewert, "Novel X-ray Backscatter Technique for Detection of Dangerous Materials: Application to Aviation and Port Security", Journal of Instrumentation, 8, September (2013), 09017.

[11] M. Willcox and G. Downes, "A brief Description of NDT Techniques", Insight NDT Equipment Limited, 2003, (2000). www.InsightNDT.com

[12] J. Brett. Ingold and AMMTIAC Rome NY, "Selecting a Nondestructive Testing Method, Part VI: Thermal/Infrared Inspection Techniques-Thermography", techsolutions08, , The AMMTIAC Quarterly, 3(2), (2006), 9-12. Related article [7] Hardy, G., "Thermal Inspection," ASM Metals Handbook, Ninth Edition, Nondestructive Evaluation and Quality Control, ASM International, 17, 396-404. http://ammtiac.alionscience.com/quartely

[13] Radiography Testing-NDT InspectionTWI Ltd, The Welding Institute TWI Ltd, Grant Park, Great Abington, Cambridge CB21 6AL, United Kingdom, (2015).

www.twi-global.com/capabilities/...testing/ndt.../radiography-testing/

[14] Niazi Ali Haj Omer Mohammed, "Estimation of Radiation Dose Received by the Radiation Workers during Radiographic Testing", M.Sc. thesis in Radiation Protection and Environment, Atomic Energy Council, Sudan Academy of Sciences, August (2013).

http://www.iaea.org/inis/collection/NCLCollectionStore/_Public/45/114/45114835.pdf

[15] Corrosion and Erosion: "Inspection Solutions for Detection, Sizing and Monitoring", General Electric Company GE Inspection Technologies, GEIT-10017EN (06/10), (2010). www.geit.com.

[16] E. Bardal and J. M. Durgli, "Corrosion Detection and Diagnosis", Materials Science and Technology, in Encyclopedia of Life Support System, Developed under the Auspices of the UNESCO, Eolss Publishers,Oxford,UK,(2004). http://www.eolss.net/sample-chapters/c05/e6-3604-04.pdf

[17] J. H. Hubbell and S. M. Seltzer, "Tables of X-Ray Mass Attenuation Coefficients and Mass Energy-Absorption Coefficients from $1 \mathrm{keV}$ to $20 \mathrm{MeV}$ for Elements $\mathrm{Z}=1$ to 92 and 48 Additional Substances of Dosimetric Interest", National Institute of Standard and Technology (NIST), Physical Measurement Laboratory, 19, (2015). http://www.nist.gov/pml/data/xraycoef/index.cfm/

[18] A. J. Ball, "Measuring Physical Properties at the Surface of a Comet Nucleus", Ph.D. Thesis. Units for Space Science and Astrophysics, University of Kent, Canterbury, UK, December (1997). https://kar.kent.ac.uk/23088/1/Ball_CometNucleus_Thesis_Dec_1997.pdf

[19] A. J. Ball, C. J. Solomon and J. C. Zarnecki, "The Response of Gamma Backscatter Density Gauges to Spatial Inhomogensity-an Extension of the Single Scattering Model", Nuclear Instruments and Methods in Physics Research B, 140, (1998) 449-462. www.mssl.ucl.ac.uk/www_detector/rosetta/nimb.pdf 